\title{
Demir Eksikliği Anemisi Olan Okul Öncesi Erkek Çocuklarda D Vitamini ve Çinko Düzeylerinin Değerlendirilmesi
}

\author{
İsmail Gürkan ÇIKIM 國, Filiz ALKAN BAYLAN 國 ${ }^{2}$
}

\begin{abstract}
ÖZ
Amaç: Yapılan bu çalışmada, demir eksikliği anemisi (DEA) olan okul öncesi erkek çocuklarda birçok yaşamsal reaksiyonda rol oynayan $\mathrm{D}$ vitamini ve çinko düzeylerinin de etkilenip sağlık sorunlarına yol açabileceği düşünülerek çinko ve D vitamini düzeylerinde değişim olup olmadığının araştırılması amaçlandı.

Gereç ve Yöntemler: Çalışmaya 2-6 yaş grubunda olan okul öncesi dönemdeki DEA tanısı alan 30 erkek çocuk (Grup I) ve tamamen sağlıklı 30 erkek çocukta (Grup II) yapıldı. Çalışmada, hemoglobin (Hb), hematokrit (Htc), MCV, RDW, Demir, Demir bağlama, Ferritin, Çinko, D vitamini düzeyleri değerlendirildi.

Bulgular: D vitamini, Çinko düzeyleri açısından; Grup I, grup II'ye göre düşüktü $(\mathrm{p}<0.05)$. Ayrıca $\mathrm{Hb}, \mathrm{Htc}, \mathrm{MCV}$, RDW, Demir, Demir Bağlama ve Ferritin düzeyleri de anemik çocukların yer aldığı Grup I' de daha düşüktü ( $<<0.05$ ). Yapılan analize göre hemoglobin değeri ile çinko düzeyleri arasında zayıf düzeyde, hemoglobin değeri ile D vitamini arasında ise orta düzeyde, pozitif yönlü ve istatistiksel olarak anlamlı bir iliş̧ki vardı.

Sonuç: D vitamini metabolizmasında, böbrekte yer alan aktif 1-25 (OH) D'yi oluşturan 1-alfa hidroksilaz enzimi demir içerdiğinden, DEA olanlarda aktif $\mathrm{D}$ vitamini sentezinin engelleneceği, ayrıca $\mathrm{D}$ vitamini eksikliğinde, inflamatuar yanıtın aktive olacağı, böylece barsaktan kana demir geçişini sağlayan ferroportin proteininin yıkımını hızlandıracağı ve neticesinde DEA meydana geleceği düşünülmektedir. Sonuç olarak bu çalı̧̧ada, DEA ile birlikte, D vitamini ve çinko düzeylerinin azaldığı tespit edildi. DEA saptanan okul öncesi çocuklarda, D vitamini ve çinko düzeylerinin belirlenerek, bu çocukların diyetlerine, D vitamini ile birlikte çinko ilave edilmesinin sağlıkları açısından gerekli olduğu düşünüldü.

Anahtar Kelimeler: Okul öncesi çocuklar; demir eksikliği anemisi; ferritin; D vitamini; çinko.
\end{abstract}

\section{Evaluation of Vitamin D and Zinc Levels in Pre-School Boys with Iron Deficiency Anemia}

\begin{abstract}
Aim: In this study, it was aimed to investigate whether there is a change in zinc and vitamin D levels, considering that vitamin $\mathrm{D}$ and zinc levels, which play a role in many vital reactions in preschool boys with iron deficiency anemia (IDA), may also be affected and cause health problems.

Material and Methods: The study was performed on 30 boys (Group I) and 30 completely healthy boys (Group II) who were diagnosed with IDA in the pre-school age group of 2-6 years. In the study, hemoglobin $(\mathrm{Hb})$, hematocrit (Htc), MCV, RDW, Iron, Iron binding, Ferritin, Zinc and vitamin D levels were evaluated.

Results: In terms of vitamin D, and zinc levels; Group I levels were lower than group II ( $\mathrm{p}<0.05)$. In addition, Hb, Htc, $\mathrm{MCV}, \mathrm{RDW}$, Iron, Iron Binding and Ferritin levels were lower in Group I, which included anemic children ( $<0.05$ ). There was a moderate, positive and statistically significant correlation between the vitamin vitamin.

Conclusion: In vitamin D metabolism, since the 1-alpha hydroxylase enzyme that forms 1-25 (OH) D in the kidney contains iron, active vitamin D synthesis will be blocked in those with DEA, and the inflammatory response will be activated in vitamin D deficiency, thus, iron from the intestine to the blood. It is thought that the ferroportin protein that enables its passage will accelerate the destruction and as a result, DEA will occur. As a result, in this study, it was found that vitamin D and zinc levels decreased with IDA. Vitamin D and zinc levels were determined in preschool children with IDA, and it was thought that adding zinc along with vitamin D to the diets of these children was necessary for their
\end{abstract}

1 Adıyaman Üniversitesi Tıp Fakültesi Tıbbi Biyokimya AD, Adıyaman, TÜRKIYE

2 Kahramanmaraş Sütçü İmam Üniversitesi Tıp Fakültesi Tıbbi Biyokimya AD, Kahramanmaraş, TÜRKIYE

Sorumlu Yazar / Corresponding Author: Filiz ALKAN BAYLAN, e-mail: drfilizalkan@gmail.com

Geliş Tarihi / Received: 09.04.2021, Kabul Tarihi / Accepted: 28.05.2021 
health.

Keywords: Pre-school children; iron deficiency anemia; ferritin; vitamin D; zinc

\section{GIRIȘ}

Demir eksikliği anemisi (DEA) tüm dünyada olduğu gibi ülkemizde de s1k olarak görülmektedir. DEA, Dünya Sağlık Örgütü verilerine göre gelişmiş ülkelerde \% 8, diğer ülkelerde \% 36 oranında olup, okul öncesi çocuklarda \% 47,4, 0-5 yaş arası çocuklarda \% 80 'e kadar artmaktadır (1,2). Ülkemizde çocukluk yaş grubunda yapılan çalışmalarda, DEA oranı \% 15,2 ile \% 62,5 arasında değişmektedir $(3,4)$. Çocuklarda görülen DEA, mental ve motor işlevlerde bozulmanın öne çıktığ 1 santral sinir sistemi rahatsılıkları, hemoglobin yetersizliği nedeniyle hipoksi oluşumu sonrasında, kardiyovasküler, kas-iskelet sistemi gibi çeşitli doku ve organlarda fonksiyon bozukluğu, DNA sentez yetersizliği, immün sistem gelişim kusurları gibi birçok olumsuz etkilere yol açmaktadır (5-7). D vitamini vücudun kalsiyum (Ca) ve fosfor (P) dengesini düzenleyerek kemik gelişimini sağlayan, immün sistem oluşumunda rol oynayan, kanser gelişimini engelleyen, apopitoz ve antienflamatuar özellikleri olan steroid yapıda bir moleküldür $(8,9)$. D vitamini eksikliğinin, çocukluk çağında rikets erişkinde osteomalazi oluşturmasının yanında immün sistem yetmezlikleri, haşimato, kanser, otoimmün bozukluklar, diyabet, kalp rahatsızlıkları gibi çeşitli hastalıkların gelişimine katkıda bulunduğu gösterilmiştir $(10,11)$. Çinko, DNA polimeraz, RNA polimeraz, süperoksit dismutaz, karbonik anhidraz, alkalen fosfataz, karboksipeptidaz, ve alkol dehidrogenaz gibi metaloenzimlerin yapısinda bulunmakta ve organizmayı oksidatif stresten korumaktadır (12). Ayrıca hem sentezinde ve eritroid gelişiminde önemlidir $(13,14)$. Çocuklarda çinko eksikliğinde, bilişsel yetilerde azalma, büyüme gelişme geriliği, immün sistem bozukluğu, enfeksiyonlara yatkınlı gibi olumsuz etkiler görülmektedir (15).

Yapılan bu çalışmada, demir eksikliği anemisi olan okul öncesi erkek çocuklarda birçok yaşamsal reaksiyonda rol oynayan D vitamini ve çinko düzeylerinin de etkilenip sağlık sorunlarına yol açabileceği düşünülerek çinko ve D vitamini düzeylerinde değişim olup olmadığının araştırılması amaçlanmıştır.

\section{GEREÇ VE YÖNTEMLER}

Çalışma bir şehir hastanesinde, çocuk polikliniğine halsizlik, solukluk, iştahsızlık şikayetleriyle getirilen, herhangi bir tedavi almayan, kronik hastalığı olmayan, 26 yaş grubunda olan okul öncesi dönemdeki DEA tanısı alan 30 erkek çocuk (Grup I) ve sağlam çocuk polikliniğine rutin muayene için getirilen tamamen sağlıklı 30 erkek çocukta (Grup II) yapıldı. Bu çalışmadaki DEA tanısı DSÖ kriterleri baz alınarak yapıldı (16). 2-6 yaş aralığı için hemoglobin değerlerinin alt sınırı $11 \mathrm{gr} / \mathrm{dl}$, olarak kabul edildi. Bu değerin altı ve ferritin değerleri $<12 \mathrm{ng} / \mathrm{ml}$ olanlar DEA olarak kabul edildi. Çalışmada serum çinko, ferritin, D vitamini ve hemoglobin, hematokrit, MCV, RDW, demir, demir bağlama seviyeleri değerlendirildi. Hastalardan ve kontrol grubundan 12 saatlik açlığı takiben venöz kan örnekleri alındı. Hemoglobin için K2 EDTA içeren tüpler kullanıldı. Örneklerin analizinde aşağıda belirtilen yöntemler kullanıldı.

Serumda çinko düzeyi, Beckman Coulter AU 680 (kraemer-USA) otoanalizöründe türbidimetrik olarak ölçüldü. Hemoglobin (Hb), hematokrit (Htc), MCV, RDW düzeyi, Sysmex XN-1000 (Corporation, Chuo-ku, Kobe, Japan) cihazı ile florasan akış sitometrisi yöntemi ile ölçüldü. Demir, Demir bağlama düzeyi, Roche Hitachi Cobas C501 otoanalizör cihazında (Roche Diagnostics, F.Hoffmann-La Roche Ltd, Kaiseraugst, Switzerland) kalorimetrik olarak ölçüldü. $25 \mathrm{OH} \mathrm{D}$ vitamini düzeyi, Cobas e 600 otoanalizör cihazında (Roche Diagnostics, F.Hoffmann-La Roche Ltd, Kaiseraugst, Switzerland) electrochemiluminescence immunoassay yöntemiyle ölçüldü.

$\mathrm{Bu}$ çalışma Kahramanmaraş Sütçü İmam Üniversitesi 08.03.2021/02 Numaralı etik kurul kararı ile tüm katılımcılardan bilgilendirilmiş onam alınarak yapıldı.

Araştırmada 2 farklı grup için örnek sayısının belirlenmesinde Karakükçü ve arkadaşlarının (17) demir eksikliği anemisi olan genç erişkin kadınlarda 25hidroksivitamin D düzeylerini inceleyen çalışması baz alınarak $a=0,05$ önem düzeyinde $b=0,20$ ve 0,80 testin gücünde power analizi gerçekleştirilmiştir. Buna göre 0,80 testin gücünde her gruba en az $n=17$ birey olmak üzere toplam 34 bireyin dahil edilmesini gerektirmiştir.

\section{İstatistiksel Analiz}

Veriler, Windows için SPSS 20.0 programı (SPSS, Inc, Chicago, IL, ABD) kullanılarak analiz edildi. Verilerin normal dağılıma uygunluğu Kolmogorov-Smirnov ve Shapiro-Wilk testleri ile değerlendirildi. Tanımlayıcı istatistikler ortalama \pm standart sapma olarak ifade edildi. DEA ve kontrol grupları arasında parametrelerin karşılaştırılmasında Mann-Whitney U testi kullanıldı. Korelasyon için Spearman'ın rho yöntemi kullanıldı.

\section{BULGULAR}

Çalışma, okul öncesi dönemdeki DEA tanısı alan 30 erkek çocuk (Grup I) ve sağlam çocuk polikliniğine rutin muayene için getirilen tamamen sağlıklı 30 erkek çocukta (Grup II) yapıldı. Çalışmada yaşlar arasında istatistiksel olarak anlamlı bir fark yoktu. Gruplardaki $\mathrm{Hb}$, Htc, ferritin, demir, demir bağlama, D vitamini ve çinko düzeyleri tabloda gösterildi.

Grupların parametreleri karşılaştırıldığında; Hemoglobin açısından; Grup I düzeyleri Grup II' ye göre anlamlı düşüktü $(p<0,001)$. Hematokrit açısından; Grup I, düzeyleri grup II' ye göre anlamlı düşüktü $(p<0,001)$. Demir açısından; Grup I düzeyleri Grup II' ye göre anlamlı düşüktü $(\mathrm{p}<0,001)$. Demir bağlama açısından; Grup I düzeyleri Grup II' ye göre anlamlı yüksekti $(\mathrm{p}<0,001)$. Ferritin açısından; Grup I düzeyleri Grup II' ye göre anlamlı düşüktü $(p<0,001)$. D vitamini açısından; Grup I düzeyleri Grup II' ye göre anlamlı düşüktü $(\mathrm{p}<0,001)$. Çinko açısından; Grup I düzeyleri grup II' ye göre anlamlı düşüktü $(\mathrm{p}<0,001)$. Yapılan analize göre $\mathrm{Hb}$ değeri ile çinko düzeyleri arasında zayıf düzeyde, $\mathrm{Hb}$ değeri ile $\mathrm{D}$ vitamini arasında ise orta düzeyde, pozitif yönlü ve istatistiksel olarak anlamlı bir ilişki bulundu (Tablo 1), (Tablo 2). 
Tablo 1. Çalışma gruplarının demografik ve biyokimyasal sonuçları

\begin{tabular}{|c|c|c|c|}
\hline & $\begin{array}{c}\text { DEA } \\
(n=30)\end{array}$ & $\begin{array}{l}\text { Kontrol } \\
(n=30)\end{array}$ & $\begin{array}{l}P \\
\text { değeri }\end{array}$ \\
\hline Yaş (y1l) & $3(2-6)$ & $3(2-6)$ & 0,708 \\
\hline $\mathrm{Hb}(\mathrm{gr} / \mathrm{dl})$ & $\begin{array}{c}9,9(5,6- \\
11,2)\end{array}$ & $\begin{array}{c}14,1(12,3- \\
16,7)\end{array}$ & $<0,001^{*}$ \\
\hline Htc (\%) & $\begin{array}{c}31,4(15,8- \\
35,9)\end{array}$ & $\begin{array}{c}40,2(35,6- \\
48,8)\end{array}$ & $<0,001^{*}$ \\
\hline $\mathrm{MCV}$ ( fL) & $\begin{array}{l}68,5(52,5- \\
80,9)\end{array}$ & $\begin{array}{c}84,4(77,2- \\
89,6)\end{array}$ & $<0,001 *$ \\
\hline RDW (\%) & $\begin{array}{c}17,2(14,7- \\
31,1)\end{array}$ & $\begin{array}{c}12,5(11,5- \\
15,5)\end{array}$ & $<0,001 *$ \\
\hline Demir $(\mu \mathrm{g}(\mathrm{dl})$ & $29(13-84)$ & $\begin{array}{c}104(38- \\
211)\end{array}$ & $<0,001 *$ \\
\hline $\begin{array}{l}\text { Demir } \\
\text { Bağlama } \\
(\mu \mathrm{g} / \mathrm{dl})\end{array}$ & $\begin{array}{c}393(205- \\
495)\end{array}$ & $\begin{array}{c}289(120- \\
433)\end{array}$ & $<0,001^{*}$ \\
\hline Ferritin $(\mu \mathrm{g} / \mathrm{L})$ & $\begin{array}{c}6,3(2,4- \\
11,8)\end{array}$ & $\begin{array}{c}33,8(8,3- \\
86,0)\end{array}$ & $<0,001 *$ \\
\hline Çinko ( $\mu \mathrm{g} / \mathrm{dl})$ & $69(30-105)$ & 95 (38-209) & $<0,001 *$ \\
\hline $\begin{array}{l}\text { D Vitamini } \\
(\mathrm{ng} / \mathrm{ml})\end{array}$ & $\begin{array}{c}12,0(4,4- \\
20,3)\end{array}$ & $\begin{array}{c}19,8(7,9- \\
35,9)\end{array}$ & $<0,001^{*}$ \\
\hline
\end{tabular}

* P değeri Mann-Whitney U Testine dayanmaktadır.

Tablo 2. Hemoglobin değeri ile çinko ve $\mathrm{D}$ vitamini arasındaki korelasyon

\begin{tabular}{|l|c|c|}
\hline Parametreler & r* & p \\
\hline Çinko $(\mu \mathrm{g} / \mathrm{dl})$ & 0,337 & $0,009^{*}$ \\
\hline D vitamini $(\mathrm{ng} / \mathrm{ml})$ & 0,644 & $<0,001^{*}$ \\
\hline $\mathrm{r}=$ Spearman'ın korelasyon katsayıs & & \\
\hline
\end{tabular}
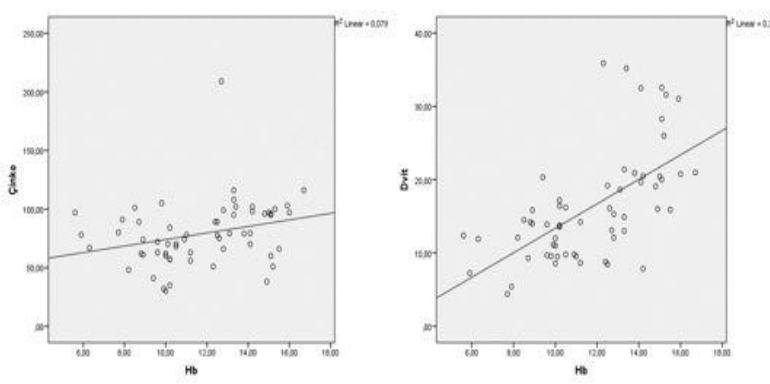

Şekil 1. Hemoglobin ile Çinko ve D vitamini arasındaki ilişki

\section{TARTIŞMA}

DEA, Türkiye'nin de dahil olduğu gelişmekte olan ve az gelişmiş ülkelerde çok ciddi halk sağlığı sorunu olarak devam etmektedir. DEA çocuklarda, özellikle santral sinir sisteminde mental gerilikten, davranış bozuklarına, öğrenme güçlüğüne kadar giden ve diğer dokuların gelişimini etkileyen, organ fonksiyon bozukluğuna yol açan hastalıktır. Türkiye de yapılan çeşitli çalışmalarda farklı sonuçlar elde edilmiş, okul öncesi çocuklarda \% 15,5-\% 19,1 olarak bulunmuştur $(18,19)$. Bu dönemde görülen DEA nedenleri arasında; hızlı büyüme, inek sütü kullanımı, beslenme alışkanlıklarının değişimi, barsak ve diğer enfeksiyonlar sayılmaktadır (20,21). Çinko, metabolizma, büyüme-gelişme ve organ fonksiyonları açısından önemli bir elementtir. Çinko eksikliğinde, büyüme gelişme geriliği, yara iyileşmesinde gecikme, cinsiyet organlarının gelişiminde aksama, tat ve koku bozuklukları, immün sistem hastalıkları görülmektedir $(22,23)$. Dünyada yapılan çeşitli çalışmalarda çocuklarda çinko eksikliğinin \% $12,5, \%$ 65, ülkemizde yapılan çalışmalarda, \% 27,8, \% 57 değişim gösterdiği tespit edilmiş ve yaş grupları ile çinko eksikliği arasında anlamlı ilişki saptanmamıştır (24-27). Demir ve çinko eksiklik belirtileri birbirleriyle benzerlik göstermekte ve her iki elementin eksikliği, semptom ve belirtileri artırmaktadır (28). Dünyada yapılan çeşitli çalışmalarda, DEA ve çinko eksikliğinin birlikte bulunduğu gösterilmiştir $(29,30)$. Gelişme geriliği olan çocuklarda yapılan bir çalışmada, çinko eksikliği ile DEA'nin birlikte olduğu tespit edilmiştir (31). Ülkemizde yapılan çeşitli çalışmalarda DEA olan çocukların, çinko düzeylerine araştırılmış ve sağlıklı gruba oranla istatistiksel olarak anlamlı derecede düşük olduğu saptanmıştır (32-34). Yaptığımız bu çalışmada, DEA' si olan grupta çinko düzeylerini, sağlıklı gruba göre anlamlı olarak düşük bulundu. Sonucumuz diğer çalışmalarla uyumlu idi. Ayrıca çalışmamızda çalışılan parametrelerden hemoglobin ile çinko arasında pozitif bir korelasyon bulundu. DEA ve çinko eksikliği genelde sosyoekonomik düzeyi düşük toplumlarda görüldüğü düşünüldüğünde, yetersiz beslenmenin, önemli nedenlerden birisi olduğu düşünülebilir. Hem sentezinde yer alan delta-aminolevülinik asit dehidrataz enzimi, DNA, RNA polimeraz enzimleri çinko varlığında çalışmaktadır (35). Çinko eksikliğinde hem sentezi, büyüme, gelişme etkilenecek anemi ve hastalık bulguları daha da derinleşecektir. Çocuklarda yapılan çalışmalarda D vitamini eksikliği prevalansı, yaş, cinsiyet ve mevsimlerle değişmekle birlikte dünyada \% 7-68, ülkemizde ise \% 8-61 oranında görülmektedir $(36,37)$. D vitamini reseptörleri birçok dokuda bulunduğundan, D vitamini eksikliğinin, infeksiyonlar, kardiyovasküler hastalıklar, alerjik, inflamatuar reaksiyonlar, kanser, psikiyatrik bozukluklar, haşimato gibi otoimmün hastalıklarda rol oynadığı gösterilmiştir (38). Yapılan çeşitli çalışmalarda D vitamini eksikliği olan çocuklarda da, DEA varlığı gösterilmiştir (39-41). Ancak bazı çalışmalarda da D vitamini eksikliği ile anemi arasında herhangi bir ilişki saptanmamıştır $(42,43)$. Yaptığımız bu çalışmada, D vitaminini, DEA'sı olan çocuklarda sağlıklı çocuklara göre anlamlı düşük bulduk. Ayrıca çalışmamızda parametrelerden hemoglobin ile D vitamini arasında pozitif bir korelasyon vardı. D vitamini metabolizmasında, böbrekte yer alan aktif 1-25 (OH) D’yi oluşturan 1-alfa hidroksilaz enzimi demir içerdiğinden, DEA olanlarda aktif D vitamini sentezinin 
engelleneceği, ayrıca D vitamini eksikliğinde, inflamatuar yanıtın aktive olacağ 1 , böylece interlökin- 6 , interlökin-1 tarafından hepsidin sentezinin artırılacağı, hepsidinin ise barsaktan kana demir geçişini sağlayan ferroportin proteininin yıkımını hızlandıracağı ve sonuç olarak DEA meydana geleceği düşünülmektedir $(17,44,45)$.

Sonuç olarak, yaptığımız bu çalışmada DEA anemisi ile birlikte, D vitamini ve çinko düzeylerinin azaldığı tespit edildi. DEA saptanan okul öncesi çocuklarda, D vitamini ve çinko düzeylerinin belirlenerek, bu çocukların diyetlerine, D vitamini ile birlikte çinko ilave edilmesinin sağlıkları açısından gerekli olduğunu düşünmekteyiz. Bu çalışmanın daha ileride yapılacak ayrıntılı çalışmalara kaynak oluşturmasını ümit etmekteyiz.

Yazarların Katkıları: Fikir/Kavram: G.Ç.; Tasarım: G.Ç.; Veri Toplama: G.Ç.; Analiz ve Yorum: F.A.B.; Literatür Taraması: F.A.B.; Makale Yazımı: G.Ç.; Eleştirel İnceleme: F.A.B.

\section{KAYNAKLAR}

1. Calvo EB, Gnazo N. Prevalance of iron deficiency in children aged 9-24 months from a large area of Argentina. Am Jour Clin Nutr. 1990; 52(3): 534-40.

2. McLean E, Cogswell M, Egli I, Wojdyla D, de Benoist B. Worldwide prevalence of anemia, WHO Vitamin and Mineral Nutrition Information System, 1993-2005. Public Health Nutr. 2009; 12(4): 444-54.

3. Gökçay G, Kılıç A. Çocuklarda demir eksikliği anemisinin epidemiyolojisi. Çocuk Sağlığı ve Hastalıkları Dergisi. 2000; 43: 3-13.

4. Gür E, Yıldız I, Celkan T. Prevalence of anemia and the risk factors among school children in İstanbul. J Trop Pediatr. 2005; 51(6): 346-50.

5. Haas JD, Brownlie T. Iron deficiency and reduced work capacity: a critical review of the research to determine a causal relationship. J Nutr. 2001; 131(2): 676-88.

6. Prentice AM, Doherty CP, Abrams SA, Cox SE, Atkinson SH, Verhoef H, et al. Hepcidin is the major predictor of erythrocyte iron incorporation in anemic African children. Blood. 2012; 119(8): 1922-8.

7. World Health Organization. Guideline: Daily Iron Supplementation in Infants and Children. Geneva: World Health Organization, 2016.

8. Herrmann M, Farrell CL, Pusceddu I, FabregatCabello N, Cavalier E. Assessment of Vitamin D Status - A Changing Landscape. Clin Chem Lab Med. 2017; 55(1): 3-26.

9. Sun J. Dietary vitamin D, Vitamin D receptor, and microbiome. Curr Opin Clin Nutr Metab Care. 2018; 21(6): 471-4.

10. Holick MF. Vitamin D: a D-lightful health perspective. Nutr Rev. 2008(10); 66: 182-94.

11. Carlberg C. Endocrine functions of vitamin D. Mol Cell Endocrinol. 2017; 453: 1-2.

12. Andreini C, Bertini I. A bioinformatics view of zinc enzymes. J Inorg Biochem. 2012; 111: 150-6.

13. Hacibekiroglu T, Basturk A, Akinci S, Bakanay SM, Ulaş T, Güney T, et al. Evaluation of serum levels of zinc, copper, and Helicobacter pylori IgG and IgA in iron deficiency anemia cases. Eur Rev Med Pharmacol Sci. 2015; 19(24): 4835-40.
14. Kelkitli E, Ozturk N, Aslan NA, Kilic-Baygutalp N, Bayraktutan Z, Kurt N, et al. Serum zinc levels in patients with iron deficiency anemia and its association with symp $\neg$ toms of iron deficiency anemia. Ann Hematol. 2016; 95(5) :751-6.

15. Motadi SA, Mbhenyane XG, Mbhatsani HV, Mabapa NS, Mamabolo RL. Prevalence of iron and zinc deficiencies among preschool children ages 3 to $5 \mathrm{y}$ in Vhembe district, Limpopo province, South Africa. Nutrition. 2015; 31(3): 452-8.

16. Yip R, Johnson C, Dallman PR. Age related changes in laboratory values used in diagnosis of anemia and iron deficiency. Am J Clin Nutr. 1984; 39(3): 427-36.

17. Karaküçük Ç, Teke HÜ, Özen M, Karaman A, Aktaş F, Zararsız G. Demir eksikliği anemisi olan genç erişkin kadınlarda 25-Hidroksivitamin D düzeyleri. Türk Klinik Biyokimya Derg. 2013; 11(3): 105-11.

18. Kılınç M, Yüregir GT, Ekerbiçer H. Anaemia and iron deficiency anaemia in South-East Anatolia. Eur J Haematol 2002; 69(5-6): 280-83.

19. Eroğlu Y, Hiçsönmez G. Hacettepe Üniversitesi Çocuk Hastanesi'nde anemi görülme sıklığı ve nedenleri. Çocuk Sağlığı ve Hastalıkları Dergisi. 1994; 37: 267- 71.

20. Ferrara, M, Coppola, L, Coppola, A, Capozzi, L. Iron deficiency in childhood and adolescence: retrospective review. Hemotology. 2006; 11(3): 1836.

21. Pinsk V, Levy J, Moser A. Yerushalmi B. Kapelushnik, J. Efficacy and safety of intravenous iron sucrose therapy in a group of children with iron deficiency anemia. IMAJ, 2008; 10(5): 335-8.

22. Brown, KH, Wuehler, SE, Peerson, JM. The importance of zinc in human nutrition and estimation of the global prevalence of zinc deficiency. Food and Nutrition Bulletin. 2001; 22(2): 113- 25.

23. Prasad AS, Miale A Jr, Farid Z, Sandstead HH, Schulert AR. Zinc metabolism in patients with the syndrome of iron deficiency anemia, hepatosplenomegaly, dwarfism, and hypogonadism. J Lab Clin Med. 1963; 61: 537-49

24. Kapil U, Jain K. Magnitude of zinc deficiency amongst under five children in India. Indian J Pediatr. 2011; 78(9): 1069-72.

25. Abbaspour N, Wegmueller R, Kelishadi R, Schulin R, Hurrell RF. Zinc status as compared to zinc intake and iron status: A case study of Iranian populations from Isfahan Province. Int J Vitam Nutr Res. 2013; 83(6): 335-45.

26. Kılıçbay F. Bursa ilinde 1-16 yaş çocuklarda çinko eksikliği prevalansı [Uzmanlık Tezi]. Bursa: Uludağ Üniversitesi Tıp Fakültesi; 2005.

27. Vurallı D. İlkokul çağındaki çocuklarda A vitamini ve çinko düzeyinin belirlenmesi ve etki eden faktörlerin değerlendirilmesi [Uzmanlık Tezi]. Ankara: Gazi Üniversitesi Tıp Fakültesi; 2010.

28. Lönnerdal B. Dietary factors influencing zinc absorption. J Nutr 2000; 130(5): 1378-83.

29. De Brito NJ, Rocha ED, de Araujo Silva A, Costa JB, Franca MC, das Gracas Almeida M, et al. Oral zinc supplementation decreases the serum iron concentration in healthy schoolchildren: A pilot study. Nutrients. 2014; 6(9): 3460-73. 
30. Soofi S, Cousens S, Iqbal SP, Akhund T, Khan J, Ahmed I, et al. Effect of provision of daily zinc and iron with several micronutrients on growth and morbidity among young children in Pakistan: A cluster-randomised trial. Lancet. 2013; 382(9886): 2940.

31. Karal Y. Çocuklarda Demir Eksikliği Anemisinde Çinkonun Önemi. Klinik Tıp Pediatri Dergisi. 2016; 8(3): 11-6.

32. Erdoğan S, Akyol B, Önal H, Önal Z, Keleş ES. Demir eksikliği anemisinde serum çinko düzeylerinin değerlendirilmesi. Çocuk Dergisi. 2003; 3(1): 49-55.

33. Arcagök B, Özdemir N, Yıldız İ, Celkan T. Çocukluk çağında demir eksikliğinin kan çinko düzeyi ile ilişkisi. Çocuk Sağlığı ve Hastalıkları Dergisi. 2013; 56: 63-70.

34. Şahin Y, Şahin DA. Demir eksikliği anemisinde serum çinko düzeylerinin değerlendirilmesi. Göztepe Tip Dergisi. 2007; 22(2): 53-7.

35. Besur S, Hou W, Schmeltzer P, Bonkovsky HL. Clinically important fe $\neg$ atures of porphyrin and heme metabolism and the porphyrias. Metabolites. 2014; 4(4): 977-1006.

36. Saggese G, Vierucci F, Boot AM, Czech-Kowalska J, Weber G, Camargo CA Jr, et al. Vitamin D in childhood and adolescence: an expert position statement. Eur J Pediatr. 2015; 174(5): 565-76.

37. Özkan B, Karagüzel G. Çocuklarda D vitamini eksikliği, tanı, tedavi ve korunma. Saka N, Akçay T (eds). Çocuk Endokrinolojisinde Uzlaşı, Çocuk Endokrinolojisi ve Diyabet Derneği Yayınları-V. İstanbul: Nobel Tip Kitabevleri; 2014: 183-9.

38. Yin K, Agrawal DK. Vitamin D and inflammatory diseases. J Inflamm Res. 2014; 7: 69-87.

39. DeLuca HF. Metabolism of vitamin D: current status. Am J Clin Nutr 1976; 29(11): 1258-70.

40. Meredith A. Atkinson, MD, Michal L, Juhi K, Cindy N, Edgar R, et al. Vitamin D, race, and risk for anemia in children. J Pediatr. 2014; 164(1): 153-8.

41. Lee JA, Hwang JS, Hwang IT, Kim DH, Seo JH, Lim JS. Low vitamin D levels are associated with both iron deficiency and anemia in children and adolescents. Pediatr Hematol Oncol. 2015; 32(2): 99108.

42. Abdul-Razzak KK, Khoursheed AM, Altawalbeh SM, Obeidat BA, Ajlony MJ. Hb level in relation to vitamin $D$ status in healthy infants and toddlers. Public Health Nutr. 2012; 15(9): 1683-7.

43. 43.Öztürk G, Bulut E, Akyol S, Taşlıpınar MY, Giniş Z, Uçar F, Erden G. The effect of serum $25(\mathrm{OH})$ vitamin D on hemogram parameters. Dicle Medical Journal. 2014; 41(2): 332-6.

44. Ruchala P, Nemeth E. The pathophysiology and pharmacology of hepcidin. Trends Pharmacol Sci. 2014; 35(3): 155-61.

45. Zughaier SM, Alvarez JA, Sloan JH, Konrad RJ, Tangpricha $\mathrm{V}$. The role of vitamin $\mathrm{D}$ in regulating the iron-hepcidin-ferroportin axis in monocytes. J Clin Transl Endocrinol. 2014; 1(1): 19-25. 